\title{
Towards Collaborative Alignment of Engineering Networks
}

\author{
Kim Jansson, Iris Karvonen, and Mikko Uoti \\ VTT, Technical Research Centre of Finland \\ Tekniikantie 2, Espoo, P.O.Box 1000, FI-2044 Finland, \\ \{Kim.Jansson, Iris.Karvonen, Mikko.Uoti\}@VTT.fi
}

\begin{abstract}
This paper reports further development of competence management in engineering networks through the consolidation of two different approaches for competence management; the Innovation and Engineering Maturity Model and the Project Alignment concept. To support the proactive competence management in collaborative networks the paper proposes first, further development of the IEMM into a more dynamic and networked structure and second, extension of the project alignment concept from the temporary project level to the more continuous organization, network level.
\end{abstract}

Keywords: Collaborative alignment, maturity model, competence management, project alignment model.

\section{Introduction}

Networking is a reality within the Finnish marine industry. Outsourcing of activities has resulted in permanent restructuring of the industry. The change is characterized by increased competition from Asia, dynamic company rearrangements and need for fast adaptation to customer requirements. The flexibility can be supported by creating collaboration preparedness in the marine networks. One component of the preparedness is the management of the network competencies and being able to align them with what is needed in customer deliveries.

VTT and a number of industrial organizations in the marine sector are carrying out a collaborative research program, which has defined and developed an Innovation and Engineering Maturity Model for Marine Industry Networks (IEMM). The results and usage experiences are reported in [1].

Recently the COIN project (Collaboration and Interoperability in Networked Enterprises) [2] was carried out to develop innovative solutions and services for Enterprise Collaboration and Interoperability. One focus area was collaborative project management. One-of-a-kind products, like ships or large machines in marine industry, are often engineered and manufactured in projects distributed both by organization and by geographic location. Solutions to support collaborative management of collaborative projects were developed in $[3,4]$. One of the implemented solutions is the Project Alignment process and the Project Alignment Model (PAM), supported by the Project Alignment Booster software [3, 5].

L.M. Camarinha-Matos, L. Xu, and H. Afsarmanesh (Eds.): PRO-VE 2012, IFIP AICT 380, pp. 467-474, 2012.

(C) IFIP International Federation for Information Processing 2012 
This paper reports further development of competence management in engineering networks through the consolidation of the IEMM and the Project Alignment concept. The objective is "Collaborative Alignment of Engineering Networks". Chapter 2 describes the current challenges and trends of marine industry and chapter 3 presents the background research and the methodology. The development towards advanced collaborative alignment is described in chapter 4 and chapter 5 gives the conclusions.

\section{Challenges in the Marine Engineering Ecosystem}

According to the project "Performance Monitoring of and Industry Foresight for the Finnish Maritime Industry“ $[6,7]$ the global trends in the marine industries are:

- Globalisation - The centre of gravity for global trade moves further away from Europe. The developing markets need foreign skills.

- Greenness - Alternative fuels and energy forms are developed. Emission is reduced using various technologies. Products are moving from using hydraulics to electricity.

- Energy economy - Life cycle costs and in particular energy consumption is in the focus. Fuels and electricity consumption are reduced by different means.

- Cost-efficiency - Due to the general cost pressure, all on-board processes are optimised e.g. efficient design of spaces usage.

In addition to challenges also important market opportunities were identified: energyand environmental innovations, arctic knowledge, newbuildings on the growing offshore and cruise markets, retrofits and conversions of aging ro-ro and cruise fleets due to tighter environmental requirement.

To response to the market opportunities the industry needs proper knowledge, capabilities and skills available when needed. This requires that the needed competencies exist in the ecosystem and that they can be found fast when needed. Currently one major challenge for organisations, due to the demographic change because of retirements, is lost knowledge which will be difficult to replace. $[8,9,10]$. Only a fraction of this knowledge is documented and shared, which results in employees leaving without passing on enough of their valuable expertise.

As a conclusion from the current trends (networking, market and aging) there is a need to better manage the competencies, identify the gaps and take care of the knowledge transfer in collaborative networks on all levels of activity - individuals, company internal, networks, national and international. Engineering organisations need to align their skills and collaboration potential.

\section{Background Research and Methodology}

Competence management can be considered as one part of preparedness. Preparedness in general expresses how much effort has been performed to prepare for a certain task before the actual task is carried out [11]. Competence management is a large research area that can be studied from different points of view: physiological, 
managerial, educational etc. Due to limited space available only a small set of previous work is referred to, from the aspects of networking and modelling.

\subsection{Profiling and Competency Management System}

The research in the area of Collaborative Networked Organisations (CNO) has a long tradition in the European research environment. The creation and management of Virtual Organisations (VO) together with the related concept of Virtual Organisations Breeding Environment (VBE), has been studied in several projects [12].

Organisations' competencies refer to capabilities to exploit its resources. The ECOLEAD project [13] has developed a Profiling and Competency Management System for VBEs. A competency of an organisation is defined as the "organisation's capability to perform (business) processes (with partners), having the necessary resources (human, technological, physical) available, and applying certain practices, with the final aim to offer products (services, goods) to the customers".

\subsection{Maturity Models}

A maturity model is a framework that describes a number of levels at which an organization can carry out activities for a specific area of interest. Maturity models focus on different disciplines that an organization can address to improve its business. A maturity model defines a structured collection of elements that describes the characteristics of processes. There are several well established maturity models, of which the CMMI [14] is the most known and used. The models are often used to achieve two objectives: 1) to help to set process improvement objectives and priorities, 2) to appraise organisations for the sake of improvement and competence development. The COIN project developed an Enterprise Collaboration Maturity Model (ECMM) that focuses on collaboration and interoperability capabilities [2].

\subsection{Innovation and Engineering Maturity Model for Marine Industry Networks}

The IEMM model, mentioned in the introduction section, is focused on the particular needs of the marine industry sector. The success factors of tomorrow are grouped into six dimensions (Innovation, Technology, Project Management, Collaboration Internationalisation and Knowledge Management/PDM)

The six dimensions are then further divided into four to six process areas per dimension, Fig. 1. For each dimension and process area, five levels of maturity have

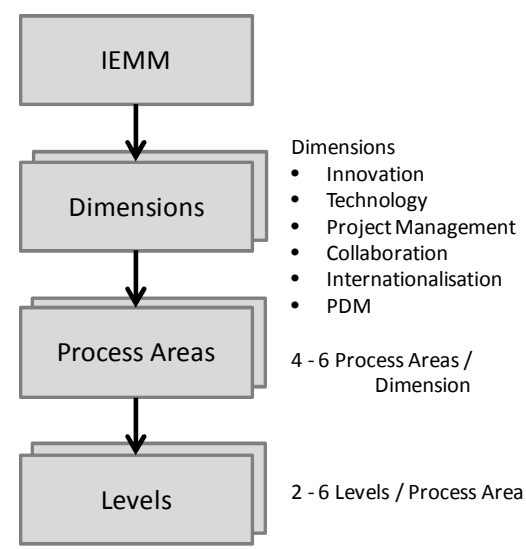

Fig. 1. First maturity model been defined. 


\subsection{Project Alignment Model}

The PAM model [5] describes the main objects or elements that need to be aligned between project demand and project partners' offering in the collaborative environment. For example, the customer may have requested that mechanical engineering in a project must be done using certain software. The partners' competences have to be aligned with this requirement; visualising the partners' competences with this software and the availability of resources. If not aligned, corrective actions may have to be taken.

The PAM model is a flexible, modular and configurable framework that consists of Alignment Elements - configurable independent entities that describe different things that need to be aligned to ensure successful completion of a project, Fig. 2. Alignment element can for example be:

- A project management task that has to be performed (e.g. define the communication management plan),

- A process that is executed during the course of the project (e.g. using local engineering standards),

- A competence (e.g. experience in using certain 3D CAD-tool), or

- A feature, attitude or cultural attribute of a project partner (e.g. openness towards new ideas).

It should be noticed that an alignment element is not part of the project work break down structure. Each alignment element may be described on different qualitative or quantitative levels. The number of levels may vary depending on the element type.

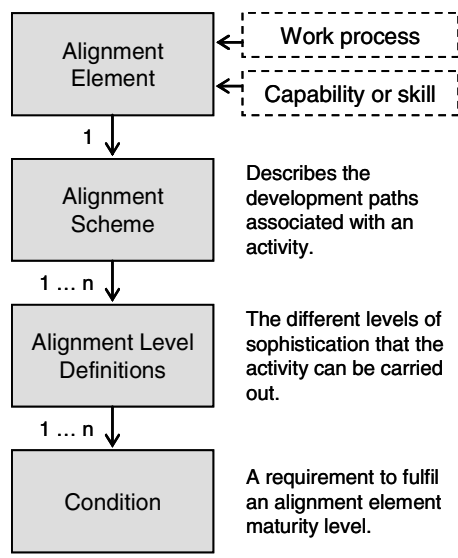

Fig. 2. Description of an Alignment Element

Although the development of the model uses structures from existing maturity models, there are some important differences. The PAM is configurable for any number of elements and levels, does not support the calculation of an overall maturity index as in e.g. CMMI, and involves non-quantitative levels, e.g. level 3 is not "better" or "more mature" than level 2 , it is just different.

\subsection{Forecasting Future Competence Needs}

A recent report [15] from the "Osaameri" project forecasts knowhow and training needs within the marine industry. The purpose of the report is to produce forecasting information that can be used by occupational, vocational high school and university level education institutions. The report is based on a large number of interviews, webquestionnaire and workshops. The identified important future marine knowledge sub-domains are: 
- Ship newbuildings (in particular special-purpose ships, cruise liners and ferries),

- Repair and retrofit,

- Off shore and arctic marine engineering,

- Ship services and maintenance,

- Equipment and systems, and

- Ship operation.

A question is how these future requirements should be considered in companies and networks. Should they be made visible when defining competencies and maturity models in the marine field? Could the concept of alignment be applied to align the future needs and the network capabilities, to identify the capability gaps?

\subsection{Research Progress and Steps}

In the used research methodology, the results from previous work have been deployed as far as possible (see Fig. 3). Achievements from the work by the authors, in the development of the IEMM and project alignment approach, have been consolidated with results from the external Osaameri results.

The research includes the following steps: 1) identification of IEMM development needs, 2) evaluation of

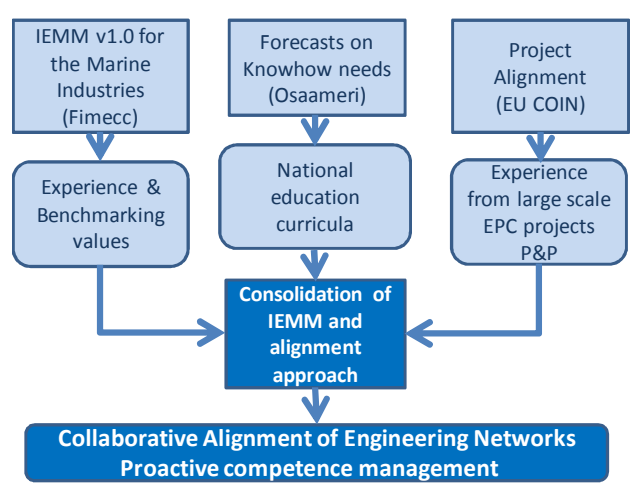

Fig. 3. Used research approach the project alignment approach and 3) consolidation of IEMM and alignment approach, extending the methodology from project alignment to proactive competence management.

\section{Consolidation of IEMM and Alignment Approach}

The objective is to develop an industrially viable approach for proactive competence management in marine industry innovation and engineering networks. The approach can afterwards be extended to cover also other engineering sectors. The following steps have been completed.

\subsection{Identification of IEMM needs}

The IEMM model was evaluated by a number of Finnish marine companies. Based on the company feedback, the development potential was identified:

- New abstraction levels: The current model is designed to be used on a company or department level. In order to apply the concepts in CNOs, there is a need to 
include additional "abstraction levels" e.g. domain-, company- and project-levels. There are no features to merge maturity levels from different organisations to get a combined "networked" maturity.

- From static to dynamic structure: The maturity analysis is based on static predefined structure. The structure corresponds to the needs of "today", but in the future the marine industry needs will change. The users should be allowed to modify and extend the model, by adding and modifying the dimensions and process areas. For example the high importance of explicit and tacit knowledge transfer due to the expected demographic.

- Support specialisation in certain niches. The needed competencies of important future marine sub-domains can be incorporated, e.g. the off-shore domain.

- Continuous updating the benchmarking data: The graphical user interface, to benchmark a company against the average within the industry is based on average values collected two years ago. The benchmarking values need continuous updating.

\subsection{Industrial Evaluation of the Project Alignment Approach}

The project alignment approach and the PAM were evaluated in a large distributed engineering project environment. The following benefits were identified:

- Shared and unified views on how to reach project objectives.

- Shared and aligned working methods and processes, including agreement on how to conduct and perform engineering work and how to use engineering software tools, and identification of learning needs.

- Identification of required external skills and knowledge.

- Providing a checklist for project management collaboration activities.

- Raised awareness of potential risks and scheduling weakness.

- Positioning and comparing project partners' attitudes and organizational cultures.

The experience and future development grand vision for collaborative project alignment were presented in [5].

\subsection{Vision for Proactive Collaborative Alignment of Engineering Networks}

This section outlines the development path towards "Collaborative Alignment of Engineering Networks". By consolidation of IEMM and alignment approach, the methodology can be extending from project alignment to proactive competence management. The development needs identified in Section 4.1 are combined with the following development potential coming from the PAM evaluation. To meet this grand vision, some new features should be included, for example:

- A knowledge base consisting of project alignment elements suitable for different domains collected into templates and instantiated into domain specific alignment models. The model can then "socially evolve" through sharing and enhancing it among the partners in a real project. 
- Links to legacy systems. Basic project information could be imported from standard project management systems using interoperability standards.

- To get a more reliable assessment of partners' capability and skills, some kind of peer review or single partner's self-assessment could be established. As an example, a grading system (one to five stars, "I like" / "I don't like") or free text comments could be used.

- Using partners' ontology to retrieve capabilities and skills semi-automatically. Industrial companies and organizations do not yet today issue any partner (or company) ontology. However in the future this could be the case. The availability of a reliable and up-to-date ontology would then remove the need for project partners to do self-assessment of their alignments status.

\section{Conclusions}

This paper reviews different approaches relating to maturity and alignment within or between organizations. Maturity models have traditionally been applied at the level of a single enterprise. This is the case also with the IEMM and ECMM approaches even if collaboration preparedness is one of their focus areas. The project alignment model is a step towards the network level assessment: it focuses on the identification of competence and preparedness gaps in a collaborative project, creating a collective view of identified gaps within the project consortium (or Virtual organization).

One of the companies' drivers for collaboration is to focus on core competencies and to be able to utilize the partners' knowledge to serve customers. To be able to successfully respond to customer requests, the network or VBE should have the needed capabilities available when needed. This requires that 1) the needed competencies exist in the network and 2) the most suitable competencies can be identified in the network.

For the latter task different partner search and selection methods can be used if there is information available about the partners' capabilities. The maturity models and alignment models can support the task if the information is available throughout all the partners for the network level.

Currently the information regarding companies' competencies, knowledge and capabilities are typically dispersed in different systems. The competencies may be managed in companies' human resource management systems at the employee level and are not as such available for the network level. The maturity models look at the process area capabilities on a company level and cannot directly use the employee level information. The alignment model extends the competence and capability aspect to cover also other types of preparedness items. Currently the methods for the definition of the data are typically different and it is not straightforward to exchange it between the different models and to make it usable at the network level.

The first condition above (availability of needed competencies) requires not only knowing and assessment of the current competencies in the network. Additionally it is important in the current dynamic environment to be able to foresee and prepare for the competencies available and needed in future. In the marine industry there is a risk 
to lose existing knowledge because of ageing and a need to extend the current knowledge to new areas as described above in Section 3.5. To support the proactive competence management in collaborative networks this paper proposes first, the extension of the project alignment concept from the temporary project level to the more continuous organization, network level and second, the forecasting and inclusion of future needs for the alignment; that is alignment between the future competence status and future competence needs at the network level.

\section{References}

1. Jansson, K.: An Innovation and Engineering Maturity Model for Marine Industry Networks. In: Camarinha-Matos, L.M., Pereira-Klen, A., Afsarmanesh, H. (eds.) PRO-VE 2011. IFIP AICT, vol. 362, pp. 253-260. Springer, Heidelberg (2011)

2. IST FP7 IP Project 216256, Collaboration and Interoperability in Networked Enterprises (COIN), http: / /www. coin-ip.eu/

3. Ollus, M., Jansson, K., Karvonen, I., Uoti, M., Riikonen, H.: On Services for Collaborative Project Management. In: Camarinha-Matos, L.M., Paraskakis, I., Afsarmanesh, H. (eds.) PRO-VE 2009. IFIP AICT, vol. 307, pp. 451-462. Springer, Heidelberg (2009)

4. Ollus, M., Jansson, K., Karvonen, I., Uoti, M., Riikonen, H.: Supporting collaborative project management. Production Planning \& Control 22(5-6), 538-553 (2011)

5. Uoti, M., Jansson, K., Karvonen, I., Ollus, M., Gusmeroli, S.: Project alignment: A configurable model and tool for managing critical shared processes in collaborative projects. In: 15th IEEE International Enterprise Distributed Object Computing Conference 2011 (EDOC), Helsinki, Finland, pp. 87-96. IEEE (2011)

6. Fimecc Innovations \& Networks Programme, http: / / www. fimecc. com

7. PROBE Performance Monitoring of and Industry Foresight for the Finnish Marine Industry. Fimecc

8. Myerson, J., Bichard, J., Erlich, A.: New demographics, new workspace: office design for the changing workforce. Gower, Surrey (2010)

9. DeLong, D.W.: Lost Knowledge - Confronting the threat of an ageing workforce. Oxford University Press, New York (2004)

10. Määttä, H.: The Challenge of the Retiring Workforce - An Overview of Knowledge Transfer Methods. In: 2011 FIMECC Innovations and Networks Research Programme (2011)

11. Tolle, M., Vesterager, J.: Virtual Enterprise Methodology. In: Karvonen, et al. (eds.) Global Engineering and Manufacturing in Enterprise Networks (GLOBEMEN), VTT Symposium, vol. 224, pp. 53-70 (2003)

12. Ermilova, E., Afsarmanesh, H.: Profiling and Competency Management in VO Breeding Environment. In: PRO-VE 2006 Conference, Helsinki - Finland, September 25-27 (2006)

13. Camarinha-Matos, L.M., Afsarmanesh (eds.): Collaborative Networks: Reference Modeling. Springer, New York (2008) ISBN-13: 978-0-387-79425-9

14. The Carnegie Mellon Software Engineering Institute, Pittsburgh, the United States. CMMI ${ }^{\circledR}$ for Development, CMU/SEI-2006-TR-008, ESC-TR-2006-008, Improving processes for better products

15. Osaamisen ennakointi meriteollisuudessa 2025 - Osameri Project (2012), Meriteollisuuden Osaamistarveraportti, http: / /www. osaameri.fi/ 